\title{
AN INVESTIGATION ON CORPORATE SOCIAL RESPONSIBILITY OF CONSTRUCTION ORGANISATIONS IN DISASTER IN SRI LANKA
}

\author{
NANAYAKKARA N.B. ${ }^{1}$, SANDANAYAKE Y.G. ${ }^{2}$ \& EKANAYAKE B.J. ${ }^{3}$ \\ 1, 2, 3 Department of Building Economics, University of Moratuwa, Sri Lanka \\ 1nishadhibn@gmail.com; 2ysandanayake@uom.lk; 3biyankaje@gmail.com
}

\begin{abstract}
Corporate Social Responsibility (CSR) is a concept, which is broadly determined as ensuring the efficacy of the organisation in integrating social and environmental considerations into organisational operations. In Sri Lankan context, a great enthusiasm can be seen among organisations to engage in CSR initiatives. Having considered the importance and impact, the study aims to investigate the importance of CSR initiatives by construction organisations in disasters in Sri Lanka. Thus, a mixed method research approach was followed as the methodology of this study. Findings are based on semi-structured interviews held with construction industry professionals. Findings of this study revealed that the implementation of CSR initiatives is more important during a disaster situation in the aspects of both affected party and aiding party. Moreover, construction organisations implement CSR during disaster situations by considering it as a mandatory responsibility of an organisation. Further, most of the construction organisations engage in CSR implementation during natural disaster situations. In practice all the construction organisations tend to engage in reactive initiatives. More importantly, it is revealed that both the organisational work force and society are benefitted through CSR implementation in disaster situations.
\end{abstract}

Keywords: Construction organisations, Corporate Social Responsibility, Disaster, Sri Lanka

\section{Introduction}

Over the last few decades, an extensive spread of CSR initiatives can be seen within the global community (Pisani, Kourula, Kolk, \& Meijer, 2017). The term CSR is initially formalized by Bowen (1953) by emphasizing the requirement of undertaking social responsibilities by entities (Cheng, Jin, Hung-Baesecke \& Chen, 2018). CSR is defined as "the continuing commitment by business to behave ethically and contribute to economic development while improving the quality of life of the workforce and their families as well as of the local community and society at large" (Holmes \& Watts, 2000). In CSR, environmental, social and economic considerations are integrated into the strategies and practices, which are followed within an organisation (Abram \& Jarzabek, 2016). Liu, Fellows, and Tuuli (2011) pointed out that under CSR, an organisation should fulfil four types of responsibilities as economic, legal, ethical and philanthropic. More importantly, CSR initiatives are implemented not only during routine organisational operations but also implemented during times of crisis (Cheng et al., 2018).

A disaster causes a significant impact on many people or entire community at large, whereas it causes economic losses, crimes, fear in crimes, suicides, psychological distress, population shifts and destruction of political and social units (Gallant, 2008). Haigh and Sutton (2012) highlighted the importance of implementing CSR towards disaster management as, to provide humanitarian assistance to save lives, alleviate suffering and protect and maintain human dignity during and after the disasters. Disasters require prompt, effective and well-coordinated response from government, private sector and voluntary organisations in order to reach speedy recovery (Singh, Srivastava \& Singh, 2017). Due to the failures of government to launch an effective disaster management policy, organisations are highly expected to participate in response, recovery, planning, and mitigation of disasters (Johnson, Connolly \& Carter, 2010).

In Sri Lankan context, organisations are seeking to adopt CSR practices (Wijerathna \& Gajanayaka, 2014). Moreover, CSR initiatives in Sri Lankan organisations are under two broad categories as internal policy level and externally focused, where the externally focused refers to the initiatives which are visible to the public at large (Sheham, 2016). Author further stated that the Sri Lankan organisations are having only a general understanding on the CSR initiatives and those organisations are implementing the initiatives without an overall policy. 
There is an integration of CSR into the construction industry, whereas environmental activities, workplace activities, marketplace activities and social activities are identified as the four major CSR types (Ulutas, 2012). As per Vijayaragunathan (2016), major drivers and barriers for the CSR implementation in Sri Lankan construction organisations are related to cost, government regulations, top management's philosophy, population growth, and stakeholders' pressure. Even though there seems a tendency of practicing CSR towards disaster management, the investigation on CSR implementation in disaster situations is lacking in the Sri Lankan construction industry. Hence, this paper aims to investigate the CSR of construction organisations in disasters in Sri Lanka.

\section{CSR Initiatives by Organisations in Disasters}

There is a growing attitude that organisations have a social obligation to act in socially, ethically and environmentally responsible way (Bhatt, 2002). The author further asserted that while doing no harm to the society, organisations have a responsibility to contribute to the well-being of the society. The aim of CSR is to make positive impacts on environment, communities, consumers and the employees (Costa \& Torrecchia, 2017). More importantly, the most concerned areas of CSR implementation are community involvement, environmental concerns, welfare and charity, products and services, and disasters (natural/ man-made) (Żychlewicz, 2015). Even though CSR initiatives are implemented by concerning all above areas, CSR initiatives acquire a significant value at a disaster situation (Ramakrishnan, Hishan, Shahabuddin \& Kanjanapathy, 2016). Disasters are unforeseen devastative events, which cause immense damages and community suffering (Singh et al., 2017). Engagement in CSR initiatives is an ideal way to provide aids for suffering community in case of a disaster (Behl \& Dutta, 2019). As per Bhatt (2002), responding on disaster situations are considered to be humanitarian rather than being professional in nature.

\section{CSR Initiatives by Construction Industry in Disasters}

Generally, the construction organisations engage in six key CSR activities such as workplace, human rights, community involvement, environmental protection, marketplace and ethical business operations (Rameezdeen, 2007). The construction organisations are capable of implementing CSR initiatives at pre and post disaster stages (Moe \& Pathranarakul, 2006). Nevertheless, the authors declared that the affected community mostly expects aids of construction organisations at post disaster stage. As per Bhatt (2002), any industry context should be rich in terms of essential resources such as material, human, technical expertise and financial in order to launch CSR initiatives during a disaster situation. According to Baroudi and Rapp (2014), construction industry possesses a strongly established countrywide network, which results in acquiring required resources in ample amount. Therefore, construction industry possesses a significant strength to engage in CSR activities towards disaster management.

The affected community is unable to cope with a disaster situation without an external assistance (Haigh \& Sutton, 2012). Therefore, the need to manage disasters through construction industry has become vital in recent years (Sathyendrakajan, Karunasena \& Wedikkara, 2012). The construction organisations engage in disaster management through building procurement, design and construction (Witt, Sharma \& Lill, 2014). Moreover, the authors emphasized that the construction organisations play a major role in responding to disasters by dealing with damaged and collapsed buildings and infrastructure and providing temporary shelter and services to affected population and also in postdisaster reconstruction efforts (Matin, 2002). As per Sui-Pheng, Raphael and Kwan (2006), above disaster management activities can be implemented by coordinating many fields in the construction industry such as professionals, volunteers, voluntary welfare organisations (VWOs) and nongovernmental organisations (NGOs), which are specialized in civil engineering, building, architecture and urban planning. Furthermore, CSR in disaster management can be implemented in forms of charity. 
Disaster management can be classified into two main approaches as proactive approach and reactive approach (Mojtahedi \& Oo, 2016). Proactive approach is referred to activities which are planned and implemented before the occurrence of a disaster and reactive approach referred to the activities implemented during and after a disaster occurrence (Moe \& Pathranarakul, 2006). The key phases of disaster management are mitigation, preparedness, response and recovery (Poser \& Dransch, 2010). As per Moe and Pathranarakul (2006), the proactive approach is undertaken at mitigation and preparedness phases while reactive approach is undertaken at response and recovery phases.

\section{Research Methodology}

Initially a comprehensive literature survey was carried out to investigate the CSR initiatives use by construction organisations globally in disaster situations. Based on the literature review, research aim was established to investigate the importance of CSR initiatives by construction organisations in disasters in Sri Lanka. In order to achieve the aim of this study, interviews under mixed method research approach were conducted among 45 construction industry practitioners attached to 45 different private sector construction organisations having CIDA Grade C2 or above using a semistructured interview guideline. The study collected importance of implementing CSR practices in a disaster and reasons for organisational engagement in CSR during a disaster related to qualitative data, and the level of organisational commitment in natural and man-made disasters, approaches followed by construction organisations when engaging in CSR initiatives in a disaster situation, level of CSR implementation as a reactive approach by construction organisations and beneficiaries in CSR implementation in a disaster related to quantitative data in order to address the research problem. The respondent profile is shown in Table 1.

Table 1: Respondent Profile - Job Responsibilities of the Respondents

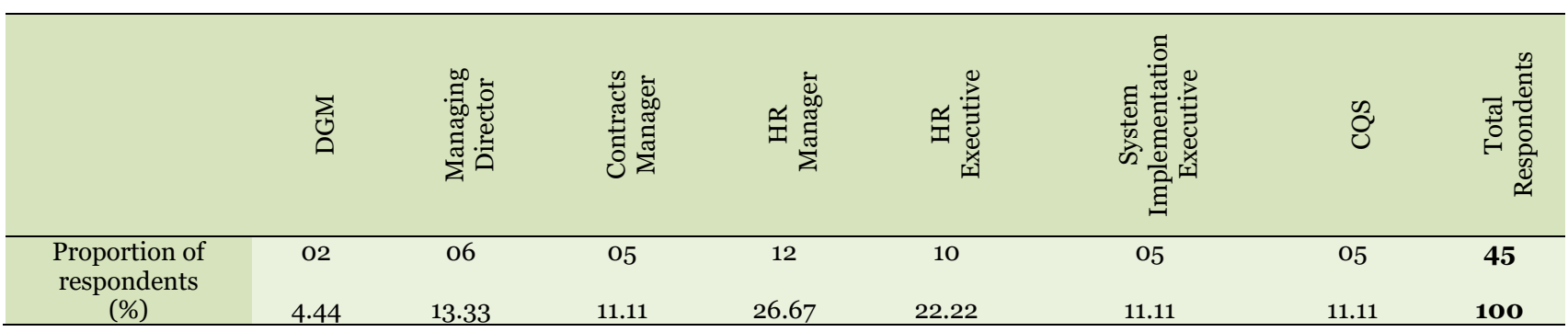

Quantitative data was analysed using descriptive statistics and qualitative data was analysed using code based content analysis. Finally, the findings are presented.

\section{Research Findings}

This study investigated the importance of implementing CSR practices and CSR initiative use by construction organisations during disaster situations in Sri Lanka. Key findings of this research study are discussed below.

\subsection{IMPORTANCE OF IMPLEMENTING CSR PRACTICES IN A DISASTER}

Initially it is required to identify the importance of CSR implementation in a disaster situation. Therefore, through semi-structured interview guideline, the importance of CSR implementation during a disaster situation was examined. All the respondents identified CSR as an important attribute to be actively practiced by construction organisations during a disaster situation.

The reasons for considering CSR as an important attribute to be practiced during a disaster situation was further investigated. Twelve respondents identified engaging in CSR initiatives is more important during a disaster situation in order to alleviate the suffering population by bringing them back to their 
normal life pattern both physically and psychologically. For example, one respondent emphasised stating that ' $w$ hen the general public have been affected from a disaster situation, there may not be any resources left with them to continue their day today life. Therefore, someone has to voluntarily help them to come back to their normal selves, in good faith'. More importantly ten respondents raised that engagement in CSR initiatives in disasters as a fulfilment of societal responsibility.

Moreover, 06 respondents emphasised another perspective to consider CSR implementation as it provides a mutually beneficial relationship for both helping party and the affected party. Meanwhile, o5 respondents stated that CSR implementation is a better way to uplift the organisational position as a corporate body.

In the literature survey, the importance of implementing CSR towards disaster management was highlighted as, to provide humanitarian assistance to save lives, alleviate suffering and protect and maintain human dignity during and after the disasters. So the facts raised in the literature survey were confirmed in the data analysis.

\subsection{ORGANISATIONAL ENAGAGEMENT IN CSR DURING A DISASTER}

After identifying the respondent attitude towards the implementation of CSR initiatives, it is required to investigate the level of CSR engagement during a disaster situation by each organisation. All the respondents emphasized that they engage in CSR initiatives during a disaster situation. Twelve respondents identified that engaging in CSR initiatives as a mandatory responsibility of an organisation. For example, one respondent stated that 'Corporates are depending on the general public in various means. Therefore, it is a mandatory responsibility to attend with CSR approach to provide our helping hands during a disaster situation'.

Eight respondents emphasized that they engage in CSR initiatives as their organisations are capable of supplying the necessary resource requirements such as labour, plant and machinery which become essential at the post disaster stage. Most of the post-disaster projects require resources for construction projects. Therefore, construction industry is the major sector who can supply that requirement effectively than other industrial sectors.

Moreover, six respondents emphasized that a certain amount in annually allocated for the CSR projects, and with the allocated budget they engage in CSR projects during disasters. More importantly, 05 respondents highlighted the higher degree of support given by the top management to engage in CSR projects.

\subsection{ORGANISATIONAL COMMITMENT IN NATURAL AND MAN-MADE DISASTERS}

As identified in the literature survey there are mainly two types of disasters as natural and man-made disasters. Figure 1 illustrates the degree of CSR implementation at each type of disasters which is identified through the semi-structured interviews.

As per Figure 1, 24 respondents stated that their organisations engage in CSR initiatives in natural disasters. That is $73.33 \%$ out of the respondent organisations who engage in CSR initiatives during disasters. Remaining 26.67\% respondents revealed that their organisations implement CSR projects during both natural and man-made disasters. So, it is evident that most of the construction organisations mainly launch CSR initiatives in case of a natural disaster.

For the investigation on the reasons, 10 respondents emphasized that they engage in CSR projects during natural disasters as there is a higher frequency of natural disaster occurrence rather than the man-made disasters. Moreover, government directly involves in providing assistance in man-made 
disasters such as wars and conflicts. So organisations get less opportunity to alleviate the suffering during and immediately after man-made disasters.

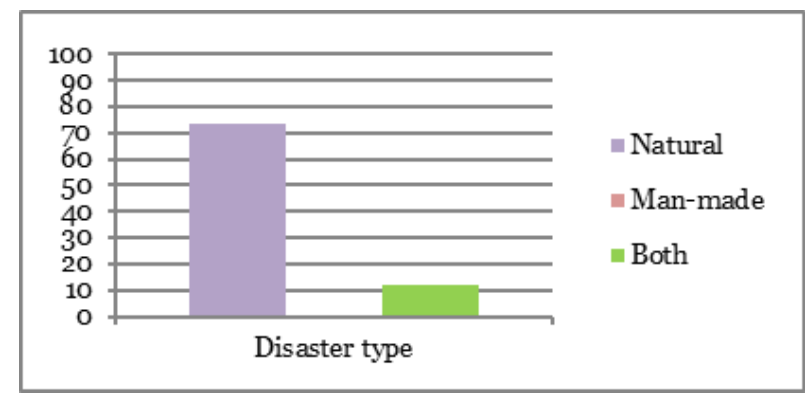

Figure 1: CSR implementation in different types of disasters

Another significant factor raised by 04 respondents is the unavailability of a responsible party for natural disasters since those are occurred naturally. Only 2 respondents highlighted that they provide relief only at natural disasters by considering the limited annual allocation for CSR projects.

\subsection{APPROACHES FOLLOWED BY CONSTRUCTION ORGANISATIONS WHEN ENGAGING IN CSR INITIATIVES IN A DISASTER SITUATION}

According to literature review, there are two major approaches to engage in CSR initiatives in a disaster as proactive and reactive. The research was further extended to collect the respondent's attitude on the most appropriate approach to be followed and the findings are illustrated in Figure 2.

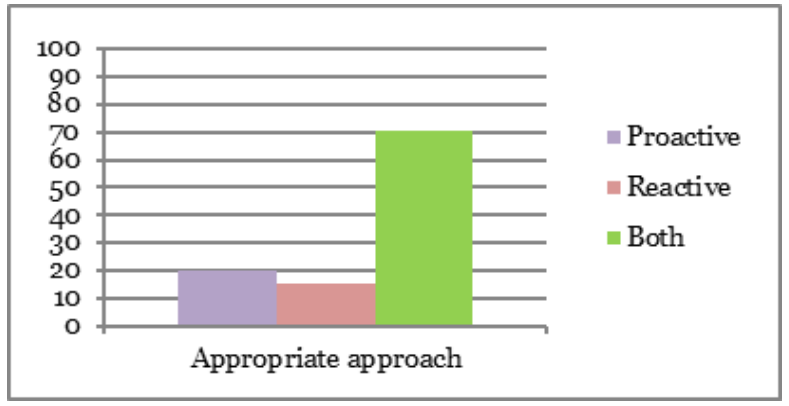

Figure 2: Respondent's attitude on the approaches to be followed when implementing CSR initiatives in a disaster situation

Although the construction organisations heavily use reactive approached, $70.73 \%$ of respondents considered that CSR initiatives should be practiced as both proactive and reactive approaches. According to one respondent, 'Most disasters are unpredictable and occur randomly. But the impact of some disasters could have been reduced by a proactive approach; still the reactive approach is also important for rectification, indemnification and improvisation'. Moreover, another respondent raised the requirement of both prevention and reinstatement.

As per Figure 2, 20\% of respondents stated the best practice is to engage in CSR initiatives as a proactive approach. According to one respondent, 'prevention is better than cure'. Moreover, 15.56\% of respondents considered reactive approach as the best suited approach to implement CSR initiatives as construction organisations can actively participate in relief programs with the prevailing resources and capabilities of their organisations.

However, for the question on actual level of interference in each approach by construction organisations, all the respondents emphasized that their organisations only follow reactive approach 
when implementing CSR initiatives in a disaster situation. The major reasons highlighted by respondents for practicing CSR only as a reactive approach are the less knowledge on pre-disaster management activities, limited financial resources and lack of time. Hence, the following section presents the findings on CSR initiatives as a reactive approach by construction organisations in Sri Lanka.

\subsection{IMPLEMENTATION OF CSR AS A REACTIVE APPROACH BY CONSTRUCTION ORGANISATIONS}

According to literature review, reactive approach can be categorized into two stages as response and recovery. Study was further extended to investigate the organisational commitment at each stage. Figure 3 illustrates the CSR implementation in post-disaster stages by construction organisations.

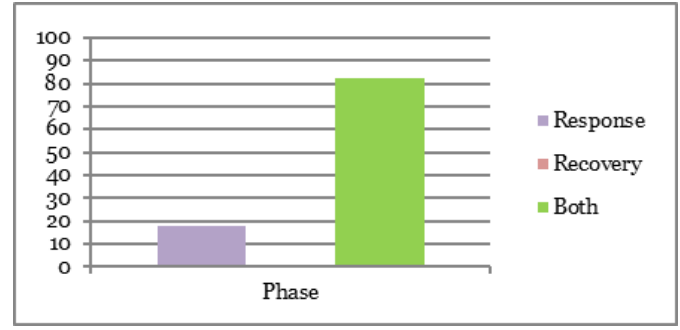

Figure 3: CSR implementation stages in a post-disaster situation by construction organisations

As per Figure 3, 82.22\% respondents emphasized that their organisations implement CSR initiatives in both phases. Only $17.78 \%$ of respondents stated that their organisations implement CSR initiatives only during the response phase. It was revealed that none of the organisations engage in CSR initiatives only during the recovery phase.

After questioning about the organisational practice, respondent attitude is obtained regarding the appropriate phases to be followed. $75.56 \%$ respondents identified that CSR initiatives should be implemented in both phases. For example, one respondent emphasised that 'CSR activities can be effectively launched when those are practiced in both the phases'. Through response phase emergency assistance can be provided, while recovery phase is required to bring back affected people to their normal life pattern both physically and mentally.

9.76\% of the respondents highlighted the availability of a clear channel to address the disaster situations immediately after it's occurred. The focus on disaster management gets diminished gradually with the time. Hence, the involvement to the recovery phase is not at a better position. On the other hand, remaining $15.56 \%$ of respondents consider recovery phase as the most appropriate. As per one respondent, 'Recovery phase is the most cost intensive phase. So, it is better if the corporate organisations allocate the whole budget for recovery phase while the collective public commit to response phase'.

\subsection{BENEFICIARIES IN CSR IMPLEMENTATION IN A DISASTER}

Last question in the interview guideline is based on the community which is focused by the construction organisations when implementing CSR initiatives. 80\% of respondent organisations provide relief to both in-house organisational work force and to the society. Only $4.44 \%$ of respondents stated that they provide relief only for the society. Both the organisational work force and society are considered as valuable assets for a construction organisation. The organisational successfulness depends on both parties. So, $80 \%$ of the organisations implement CSR initiatives for both the parties. 


\section{Conclusions}

The CSR is a concept, which was developing in the global context over the decades. Moreover, there can be seen an immense enhancement for CSR concept in Sri Lankan context including the construction industry. The construction organisations engage in numerous CSR projects by aiming variety of social benefits such as enhance environmental sustainability, provide welfare and charity for the betterment of the society. Moreover, there can be identified an involvement in CSR projects during disaster situations.

There are two categories of disasters as natural and man-made disasters. In any type of disaster, mainly there are two stages as pre-disaster and post disaster, whereas both the stages need an effective management. Pre-disaster situation can be managed through proactive approaches, while post disaster situation can be managed through reactive approaches. Basically, reactive approach can be implemented in two main phases as response and recovery phase. Disasters have the capability to pull down the living status of the whole community. Therefore, there emerges a requirement to provide relief for the affected community.

During a disaster situation, all most all the society get cooperated to supply aids, whereas most of them are engaging in a voluntary service. Being among the voluntary community, construction organisations also play a vital role. Assistance given by construction organisations spreads upon a wider area and it is given through engagement in CSR initiatives. They highly believe that aiding the affected community is a mandatory responsibility of construction organisations. Industry practitioners tend to supply aids mostly in case of a natural disaster. That is by considering the higher frequency of natural disasters relative to man-made disasters. Even though there is a requirement to provide assistance in both the pre-disaster and post disaster stages, more often construction organisations focus on post disaster stage of a disaster by concerning time constraints and less budget allocation.

During the post disaster stage, construction organisations engage in CSR implementation both as response phase activities and recovery phase activities. That is by concerning the effectiveness achieved through engaging in both the phases. During the response phase, CSR initiatives are implemented to provide emergency assistance, while CSR initiatives are implemented in recovery phase in order to alleviate the suffering by bringing back affected community to their normal life pattern.

\section{References}

Abram, M., and Jarzabek, J. 2016. Corporate social responsibility in hotel industry: environmental implications. Ecocycles, 2(2), 9-16.

Baroudi, B. and R. Rapp, R. 2014. Stakeholder management in disaster restoration projects. International Journal of Disaster Resilience in the Built Environment, 5(2), pp.182-193.

Behl, A. and Dutta, P. 2019. Social and financial aid for disaster relief operations using CSR and crowdfunding. Benchmarking: An International Journal, 27(2), pp.732-759.

Bhatt, M. 2002. Corporate social responsibility and natural disaster reduction: Local overview of Gujarat.

Cheng, Y., Jin, Y., Hung-Baesecke, C. and Chen, Y. 2018. Mobile Corporate Social Responsibility (mCSR): Examining Publics' Responses to CSR-Based Initiatives in Natural Disasters. International Journal of Strategic Communication, 13(1), pp.7693.

Costa, M. and Torrecchia, P. 2017. The Concept of Value for CSR: A Debate Drawn from Italian Classical Accounting. Corporate Social Responsibility and Environmental Management, 25(2), pp.113-123.

Haigh, R. and Sutton, R. 2012. Strategies for the effective engagement of multi-national construction enterprises in post-disaster building and infrastructure projects. International Journal of Disaster Resilience in the Built Environment, $3(3), \mathrm{pp} .270-282$.

Holmes L, Watts R. 2000. Corporate Social Responsibility: Making Good Business Sense. World Business Council for Sustainable Development.

ISO, November 2010. ISO 26000 - Guidance on Social Responsibility. The International Organization for Standardization, Geneva, Switzerland. 
Johnson, B., Connolly, E. and Carter, T. 2010. Corporate social responsibility: the role of Fortune 100 companies in domestic and international natural disasters. Corporate Social Responsibility and Environmental Management, 18(6), pp.352-369. Lin Moe, T. and Pathranarakul, P. 2006. An integrated approach to natural disaster management. Disaster Prevention and Management: An International Journal, 15(3), pp.396-413.

Liu, A., Fellows, R. and Tuuli, M. 2011. The role of corporate citizenship values in promoting corporate social performance: towards a conceptual model and a research agenda. Construction Management and Economics, 29(2), pp.173-183.

Matin, N. 2002. Corporate social responsibility and natural disaster reduction: insights from Bangladesh. UK Department for International Development, London.

Mojtahedi, M. and Oo, B. 2017. Critical attributes for proactive engagement of stakeholders in disaster risk management. International Journal of Disaster Risk Reduction, 21, pp.35-43.

Pisani, N., Kourula, A., Kolk, A. and Meijer, R. 2017. How global is international CSR research? Insights and recommendations from a systematic review. Journal of World Business, 52(5), pp.591-614.

Poser, K. and Dransch, D. 2010, Volunteered geographic information for disaster management with application to rapid flood damage estimation, Geomatica, 64(1), pp. 89-98.

Ramakrishnan, S., Hishan, S., Shahabuddin, A., and Kanjanapathy, M. 2016. The Role of Corporate Social Responsibility in Flood Mitigation among the Listed Insurance Companies in Malaysia. In Asia International Conference (pp. 86-90).

Rameezdeen, R. (2007). IMAGE OF THE CONSTRUCTION INDUSTRY (pp. 76-87). CIB General Secreteriat. Retrieved from https://www.irbnet.de/daten/iconda/CIB6126.pdf

Sathyendrakajan, N., Karunasena, G. and Wedikkara, C. 2012. Exploring Capacity of Construction Industry Post Disaster Housing Reconstruction. Built-Environment Sri Lanka, 11(1), p.2.

Sheham, A. 2016. Survey on Corporate Social Responsibility in Sri Lanka. (Report No. 85, 1-18). Department of Accountancy \& Finance, Faculty of Management \& Commerce South Eastern University of Sri Lanka.

Singh, L., Srivastava, A. and Singh, S. 2017, Role of corporate sector \& industries in corporate social responsibility for disaster management, Quality - Access to Success, 18(159), pp. 58-61.

Sui Pheng, L., Raphael, B. and Kwan Kit, W. 2006. Tsunamis. Structural Survey, 24(5), pp.378-396.

Ulutas, D. 2012. Corporate social responsibility in construction industry. Istanbul Technical University.

Vijayaragunathan, S. 2016. Sustainability practices for competitive advantage in Sri Lankan construction industry. 7 th International Conference on Sustainable Built Environment (pp. 1-10). Kandy: University of Moratuwa.

Wijerathna, I. and Gajanayaka, R. 2014. The Socio-Economic Impact of Corporate Social Responsibility Practices in Sri Lankan Tea Manufacturing Companies (Special Reference to Kandy District). Kelaniya Journal of Management, 2(1), p.113. Witt, E., Sharma, K. and Lill, I. 2014. Mapping Construction Industry Roles to the Disaster Management Cycle. Procedia Economics and Finance, 18, pp.103-110.

Żychlewicz, M. 2015. Corporate benefits of CSR activities. Journal of Corporate Responsibility and Leadership, 1(1), p.85. 